\title{
Intramolecular Electronic Interaction in Pyridinyl Diradicals Temperature Dependence and Electronic Structure
}

\author{
Michiуa Iтон \\ Faculty of Pharmaceutical Sciences, The University of Tokyo 1 )
}

(Received November 7, 1972)

\begin{abstract}
Pyridinyl diradicals, $\mathrm{Py}(\mathrm{Ac})^{\cdot}\left(\mathrm{CH}_{2}\right)_{n} \mathrm{Py}(\mathrm{Ac})^{\circ}$, (in which $\mathrm{Py}(\mathrm{Ac})^{\bullet}$ is $4-\mathrm{CH}_{3} \mathrm{OCC}_{5} \mathrm{H}_{4} \mathrm{~N}^{\cdot}$, and $n=3$ and 4 ) were obtained. Intramolecular electronic interaction between two 4 -acetylpyridinyl moieties in the diradical $n=3$ was observed. Temperature dependence of absorption spectra suggests the conformational equilibrium between the open and closed forms in the diradical $n=3(-\Delta H=7.6 \mathrm{kcal}$ and $\Delta S=-14 \mathrm{e} . \mathrm{u}$.$) . Electronic absorption$ spectroscopy and SCF-CI molecular orbital calculation reveal that a strong visible absorption band in the closed form diradical $(n=3)$ is ascribed to a charge-transfer band between two pyridinyl moieties.
\end{abstract}

Importance and efficiency of the trimethylene chain were pointed out in the intramolecular excimer formation of 1,3-di-phenylpropane by Hirayama. ${ }^{2)}$ Itoh and Kosower ${ }^{3)}$ reported the intramolecular association between two pyridinyl moieties in 1,1'-trimethylene-bis $(4-$ carbomethoxypyridinyl), (4-carbomethoxypyridinyl moiety is abbreviated to $\mathrm{Py}$ (Car) ${ }^{\cdot}$ or Car hereafter.). Subsequently, Itoh ${ }^{4}$ demonstrated intramolecular electronic interaction in the pyridinyl cation radicals, $\mathrm{Py}(\mathrm{Car})^{+}\left(\mathrm{CH}_{2}\right)_{n} \mathrm{Py}(\mathrm{Car})^{\cdot}$, (where $\mathrm{Py}(\mathrm{Car})^{+}$is pyridinium cation), which could not be observed in the mixed solution of the pyridinyl and pyridinium salt without tri- or tetramethylene chain. In the previous paper, ${ }^{5)}$ the present author reported the intramolecular interaction and temperature-dependent conformational equilibrium in the pyridinyl hetero diradical, $\mathrm{Py}(\mathrm{Ac})^{\cdot}\left(\mathrm{CH}_{2}\right)_{3} \mathrm{Py}(\mathrm{Car})^{\circ}$. This paper demonstrates similar conformational equilibrium in the diradical,

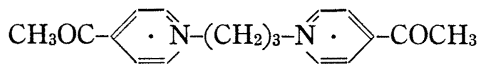

and experimental and theoretical studies of the intramolecular electronic interaction between two pyridinyls in comparison with those of homo ${ }^{3)}$ and hetero diradicals..$^{5,6)}$

\section{Result and Discussion}

\section{Electronic Absorption and Electron Spin Resonance (ESR) Spectra}

The pyridinyl diradicals ( $\mathbf{3}$ for $n=3$ and $\mathbf{4}$ for 4 ) were generated by reduction of the corresponding diiodide (bromide) with $3 \%$ sodium amalgam in acetonitrile. The procedures are described in the previous papers., ${ }^{3,4}$ The electronic absorption spectra of the 2-methyltetrahydrofuran (MTHF) solutions of $\mathbf{3}$ and $\mathbf{4}$ (at room temperature) are shown in Fig. 1. The diradical $\mathbf{3}$ shows a remarkable visible absorption band which was confirmed to be concentration independent at room temperature. 1-Methyl-4-acetylpyridinyl shows two absor-

1) Location: Bunkyo-ku, Tokyo, 113, Japan.

2) F. Hirayama, J. Chem. Phys., 42, 3163 (1965).

3) M. Itoh and E.M. Kosower, J. Am. Chem. Soc., 89, 3955 (1967); idem, ibid., 90, 1843 (1968).

4) M. Itoh, J. Am. Chem. Soc., 93, 4750 (1971).

5) M. Itoh, J. Am. Chem. Soc., 94, 1034 (1972).

6) M. Itoh, The results presented in the Japanese Symposium of Molecular Structure and Spectra, Kyoto (1971), Bull. Chem. Soc. Japan, 46, 821 (1973). 
ption maxima in $400-450 \mathrm{~nm}$ region which may be vibrational progression because of same spacing as that in the absorption at $300-320 \mathrm{~nm}$ region. The spectrum of 4 suggests no significant intramolecular interaction between two radical moieties. Therefore, the spectra of 3 and 4 shown in Fig. 1 suggest that only trimethylene chain let the diradical to show the intramolecular interaction. Table I summarizes the spectroscopic data of the diradical 3 and other diradicals reported in the previous papers, ${ }^{3,5,6)}$ in comparison with the electronic transitions which were obtained by SCF-CI calculations. ${ }^{6}$ From these results the visible absorption band in $\mathbf{3}$ may be a charge-transfer band between two pyridinyl moieties. Two UV absorption bands of $\lambda_{\max }$ 295 and $409 \mathrm{~nm}$ in the MTHF solution of 3 seem to be shifted local excitations, which decrease in intensity compared with those of $\mathbf{4}$. It seems that the decrease of the intensity in this region is attributed to the hypochro$\mathrm{mism}^{7,8)}$ and/or intensity borrowing by the charge-transfer band.

The ESR spectra of the MTHF solutions of $\mathbf{3}$ and $\mathbf{4}$ are so similar each other that significant difference could not be detected except intensity. Similar behavior of ESR hyperfine structure was observed in the diradicals $\mathrm{Py}(\mathrm{Car})^{\cdot}\left(\mathrm{CH}_{2}\right)_{3} \mathrm{Py}(\mathrm{Car})^{\cdot}$ and the cation radicals reported in the previous pa-

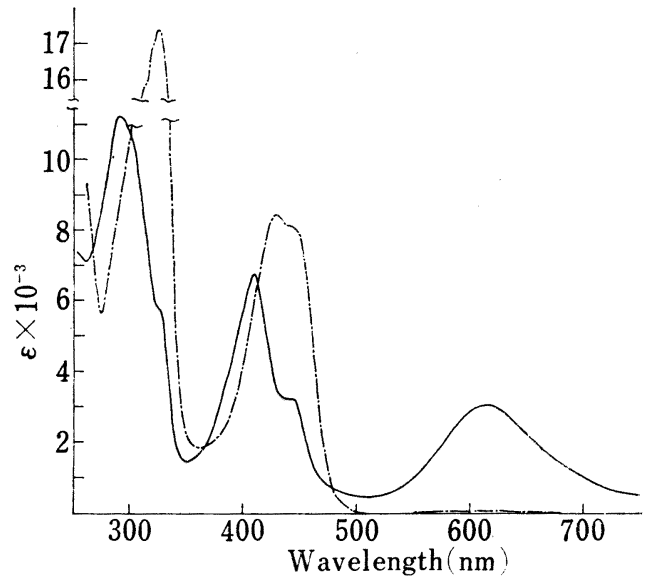

Fig. 1. Electronic Absorption Spectra of the MTHF Solutions of the Pyridinyl Diradicals, $n=3$ and 4 , at Room Temperature

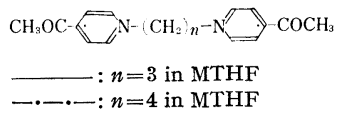
pers. $^{3,4)}$ The ESR hyperfine structure should be attributed to the open form of 3 or $\mathbf{4}$.

\section{Conformational Equilibrium of the Open and Closed Forms}

The previous paper proposed that the pyridinyl diradical, $\mathrm{Py}(\mathrm{Car})^{\cdot}\left(\mathrm{CH}_{2}\right)_{3} \mathrm{Py}(\mathrm{Car})^{\cdot}$ consists of the open and closed forms in equilibrium. However, no direct observation of the equilibrium was presented. Subsequently, the temperature dependence of the absorption spectrum in MTHF solution of the hetero diradical yielded the open and closed form equilibrium of which thermodynamic data were evaluated to be $-\Delta H=5.6 \mathrm{kcal}$ and $\Delta S=-10.5 \mathrm{eu}$., reported in the previous communication. ${ }^{5}$ Similar temperature dependence of the absorption spectra of $\mathbf{3}$ was observed, as shown in Fig. 2. While the intensities of 448- and 325-nm

TABLE I. Spectroscopic and Calculated Data of Electronic Transitions in Pyridinyl Diradicals $\operatorname{Py}(\mathrm{Ac})^{\cdot}\left(\mathrm{CH}_{2}\right)_{3} \mathrm{Py}(\mathrm{Ac})^{\cdot}$

\begin{tabular}{|c|c|c|c|c|c|c|}
\hline \multirow{2}{*}{$\begin{array}{l}\text { Obsd. } \\
\Delta E, \text { ev }\end{array}$} & \multirow{2}{*}{$\varepsilon$} & \multicolumn{5}{|c|}{ Calcd. } \\
\hline & & $\Delta E, \mathrm{ev}$ & $f^{a)}$ & $\mu_{\mathrm{x}}^{b)}$ & $\mu_{\mathrm{y}}$ & $\mu_{\mathrm{z}}$ \\
\hline $1.98^{c)}$ & $8000^{c)}$ & 1.71 & 0.795 & -0.209 & 0 & -2.293 \\
\hline $3.04^{c)}$ & $12500^{c)}$ & 3.41 & 0.218 & 0 & 0.855 & 0 \\
\hline \multirow[t]{2}{*}{$4.25^{c)}$} & $\sim 18000^{c)}$ & $\int 4.32$ & 0.915 & 0 & -1.558 & 0 \\
\hline & & 4.62 & 0.172 & 0.655 & 0 & -0.005 \\
\hline
\end{tabular}

7) I. Tinoco, Jr, J. Chem. Phys., 34, 1067 (1961); W. Rhodes, J. Am. Chem. Soc., 83, 3609 (1961).

8) D.T. Browne, J. Eisinger, and N.J. Leonard, J. Am. Chem. Soc., 90, 7302 (1968). 
$\operatorname{Py}(\mathrm{Car})^{\cdot}\left(\mathrm{CH}_{2}\right)_{3} \mathrm{Py}(\mathrm{Car})^{\cdot}$

\begin{tabular}{|c|c|c|c|c|c|c|}
\hline \multirow{2}{*}{$\begin{array}{l}\text { Obsd. } \\
\Delta E, \text { ev }\end{array}$} & \multirow{2}{*}{$\varepsilon$} & \multicolumn{5}{|c|}{ Calcd. } \\
\hline & & $\Delta E, \mathrm{ev}$ & $f^{a)}$ & $\mu_{\mathrm{x}}{ }^{b)}$ & $\mu_{\mathrm{y}}$ & $\mu_{z}$ \\
\hline $1.80^{d)}$ & $3800^{d)}$ & 1.77 & 0.880 & -0.181 & 0 & -2.374 \\
\hline $3.18^{d)}$ & $\left.4600^{d}\right)$ & 3.59 & 0.111 & 0 & 0.595 & 0 \\
\hline \multirow[t]{2}{*}{$5.16^{d)}$} & $\left.\sim 30000^{d}\right)$ & 4.41 & 1.012 & 0 & -1.621 & 0 \\
\hline & & 4.66 & 0.166 & 0.638 & 0 & 0 \\
\hline
\end{tabular}
a) oscillator strength
b) Transition moments, $x, y$ and $z$ are the molecular axes shown in Fig. 4.
c) Molar absorption coefficients of absorption maxima in 3 at $77^{\circ} \mathrm{K}$, assumed to be in the purely closed form.
d) The results in the isopentane-3-methylpentane mixed solvent at room temperature. See ref. 3.

absorptions due to 4-acetylpyridinyl decreased, the intensities of 409 - and 300 -nm regions as well as the charge-transfer band at $609 \mathrm{~nm}$ increased with decreasing temperature.

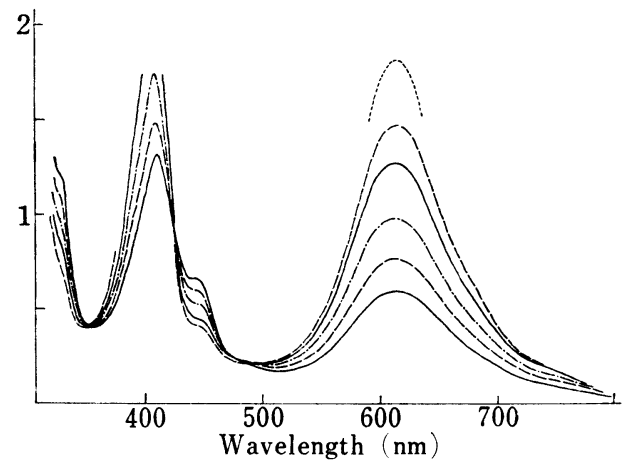

Fig. 2. Temperature Dependence of the Spectrum of 3 in MTHF

Concentration is $7.7 \times 10^{-} \mathrm{s}_{\mathrm{M}}$.

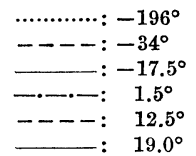

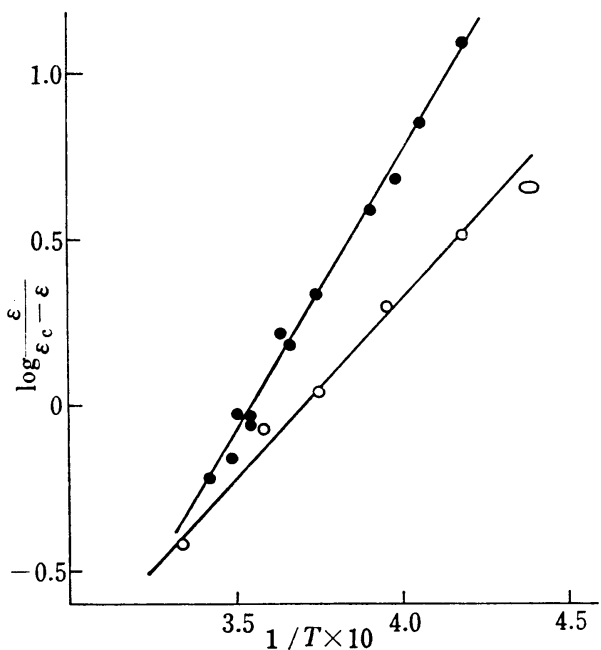

Fig. 3. Plots of $\log \frac{\varepsilon}{\varepsilon_{\mathrm{c}}-\varepsilon}$ against $1 / T$ in the Diradical 3 and the Hetero Diradical $\mathrm{Py}$ (Car) ${ }^{\circ}\left(\mathrm{CH}_{2}\right)_{3} \mathrm{Py}(\mathrm{Ac})^{\cdot}$

The thermodynamic data were obtained dy a leastsquarer fit.

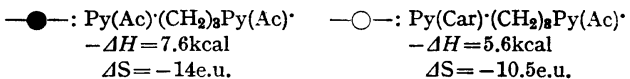

If $\varepsilon_{\mathrm{c}}$ is assumed to be a molar absorption coefficient of the closed form of $\mathbf{3}$, since the molar absorption $(\varepsilon)$ at $624 \mathrm{~nm}$ increased to approach 8000 with decreasing temperature $\left(77^{\circ} \mathrm{K}\right)$, plots of $\log \varepsilon /\left(\varepsilon_{\mathrm{c}}-\varepsilon\right)$ against $1 / T$ show a straight line in dilute solution as shown in Fig. 3. Plots for the hetero diradical $n=3$ are also shown in Fig. 3. The enthalpy $(-\Delta H)$ and entropy $(\Delta S)$ changes from the open to closed forms in 3 were evaluated to be $7.6 \mathrm{kcal}$ and -14 e.u., respectively. The thermodynamic data obtained here are compared with those on the hetero diradical, mentioned above. In the diradical $\mathrm{Py}(\mathrm{Car}) \cdot\left(\mathrm{CH}_{2}\right)_{3} \mathrm{Py}(\mathrm{Car})^{\cdot}$, no significant temperature dependence of absorption intensity was observed. The strong charge-transfer interaction of two moieties seems to make the closed form to be predominant, and to prevent the direct observation of the open and closed forms in equilibrium. 


\section{Electronic Structure of Pyridinyl Diradicals}

Most of the calculation of the radical dimers, ${ }^{9,10)}$ and also dimer radicals ${ }^{11)}$ have been made with the method of "composite molecule", which consists of configuration interaction between local excitations in the component radicals and the charge-transfer configuration in two SCF MO's in the diradical. In the previous paper, ${ }^{10)}$ Itoh and Nagakura reported semiquantitative estimation of the transition energy of the charge-transfer band in the pyridinyl dimer by the aid of equation, $\mathrm{I}-\mathrm{A}+\mathrm{C}=\Delta E$, where $\mathrm{I}$ and $\mathrm{A}$ are an ionization potential and electron affinity in the radical monomer; $\mathrm{C}$ is an electrostatic force in the charge-transfer structure, $\mathrm{Py}^{+} \mathrm{Py}^{-} ; \mathrm{I}-\mathrm{A}$ was reduced to one-center electron repulsion integral (ii/ii) in the radical. In this paper, molecular orbitals in the diradical were considered to be delocalized over two pyridinyl moieties.

The standard program for restricted $\mathrm{SCF}-\mathrm{Cl}$ procedures ${ }^{12}$ ) was used in the diradical as well as in the monoradical. Both intra- and intermolecular electron repulsions were calculated by Nishimoto-Mataga's approximation. Interatomic overlap integrals between two pyridinyls were evaluated by the aid of the data in Clementi's Table. $\left.{ }^{13}\right)$ The electronic transitions in the diradicals $\mathrm{Py}(\mathrm{Ac})^{\cdot}\left(\mathrm{CH}_{2}\right)_{3} \mathrm{Py}(\mathrm{Ac})^{\cdot}$ and $\mathrm{Py}(\mathrm{Car})^{\cdot}\left(\mathrm{CH}_{2}\right)_{3} \mathrm{Py}(\mathrm{Car})^{\cdot}$ were calculated, of which molecular geometries were assumed to be a sandwich model as shown in Fig. 4. Although molecular model says that the closed form diradical 3 does not make a sandwich structure of two parallel plains with $\sim 3.4 \AA$ spacing, and actual conformational structure seems to be non-parallel with average spacing of $\sim 3.4 \AA$, as shown in Fig. 5 , the SCF-CI calculation mentioned above was performed with a model shown in Fig. 4 for the sake of convenience. The results are summarized in Table I, in comparison with the spectral data.

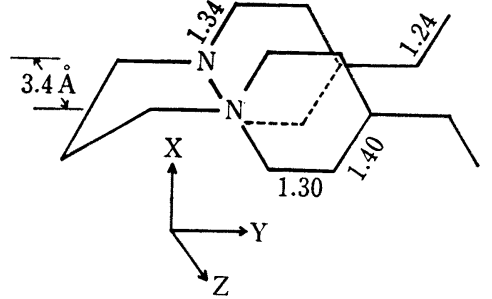

Fig. 4. Molecular Geometry of the Diradical 3 assumed in the Calculation

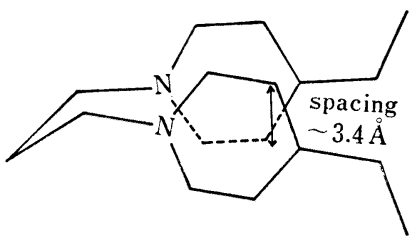

Fig. 5. A Molecular Model shows Non-parallel in the average spacing of $\sim 3.4 \AA$

The transition energies and oscillator strength obtained here show considerably good agreement with the spectral results, although no variable parameterization was made for ajusting the calculated results to the spectral data. The longest wavelength absorption bands (600-700 nm) both in $\mathrm{Py}(\mathrm{Ac})^{\cdot}\left(\mathrm{CH}_{2}\right)_{3} \mathrm{Py}(\mathrm{Ac})^{\cdot}$ and $\mathrm{Py}(\mathrm{Car})^{\cdot}\left(\mathrm{CH}_{2}\right)_{3} \mathrm{Py}(\mathrm{Car})^{\cdot}$ were really ascribed to the charge-transfer band in the diradicals from the direction of transition moment (z) shown in Table I. While the oscillator strength of $400-\mathrm{nm}$ band $(\Delta E=3.18 \mathrm{eV})$ was estimated to be rather small, compared with the observed intensity, the intensity of the chargetransfer band seems to be over-estimated. The over-estimation of intensity in the chargetransfer band seems attributed to intensity borrowing of the $\sim 400 \mathrm{~nm}$ band by the chargetransfer band. Several other sandwich models such as a twisted model ${ }^{14)}\left(\theta=10^{\circ}\right)$ and a

9) K.H. Hausser and J.N. Murrell, J. Chem. Phys., 27, 500 (1957).

10) M. Itoh and S. Nagakura, J. Am. Chem. Soc., 89, 3959 (1967).

11) A. Isbitani and S. Nagakura, Mol. Phys., 12, 1 (1967).

12) T. Shida and S. Iwata, J. Chem. Phys., 56, 2858 (1972). The results presented in the Japanese Symposium of Moleculer Structure and Spectra, Kyoto (1971).

13) E. Clementi, "Table of Atomic Functions" (IBM Co, San Jose, Calif., 1965).

14) M. Itoh, Chem. Phys. Letters, 2, 371 (1968). 
slided model along $\mathrm{x}$ axis were considered for calculations. The results suggest that the structure shown in Fig. 4 seems to be the most reasonable both in their transition energies and intensities.

\section{Experimental}

Materials-Two 1, $1^{\prime}$-trimethylene- and 1,1'-tetramethylene-bis(4-acetylpyridinium iodide or bromide) were prepared from 4-acetylpyridine and corresponding alkyldiiodide or bromide. 1,1'-Trimethylenebis(4-acetylpyridinium bromide), mp 105-107 (Anal. Calcd. for $\mathrm{C}_{17} \mathrm{H}_{20} \mathrm{O}_{2} \mathrm{~N}_{2} \mathrm{Br}_{2}: \mathrm{C}, 43.03 ; \mathrm{H}, 4.22 ; \mathrm{N}$, 5.91. Found: $\mathrm{C}, 43.36 ; \mathrm{H}, 4.29 ; \mathrm{N}, 5.64)$. 1,1'-Tetramethylene-bis(4-acetylpyridinium iodide), $\mathrm{mp} 258^{\circ}$ (Anal. Calcd. for $\mathrm{C}_{18} \mathrm{H}_{22} \mathrm{O}_{2} \mathrm{~N}_{2} \mathrm{I}_{2}: \mathrm{C}, 39.13 ; \mathrm{H}, 3.98 ; \mathrm{N}, 5.07$. Found: C, 38.65; H, 4.00; N, 4.78). Purifications of the solvents were mentioned in the previous papers. ${ }^{3,4,10}$ )

Preparation of the Diradicals_- bis(pyridinium iodide or bromide) $(\sim 0.02 \mathrm{~g})$ and $3 \%$ sodium amalgam $(\sim 0.2 \mathrm{~g})$ were sealed into the reaction tube. After evacuation to $\sim 10^{-5}$ torr, degassed acetonitrile $(\sim 7 \mathrm{ml})$ was introduced by using a vacuum line. The reaction tube was shaken some times for about $2-5 \mathrm{hr}$ at room temperature. The solvent (acetonitrile) was removed by using a vacuum line. The diradical was extracted with MTHF $(\sim 10 \mathrm{ml})$.

Measurements-Electronic absorption spectra were determined with a Cary Model 11 recording spectrophotometer. A quartz dewer with windows was used for low temperature spectra. ESR measurements were made with JEOLCO P-10 spectrometer with $100 \mathrm{kc}$ modulation. Determination of concentration of the diradical was done using the same procedures as described in the previous papers. ${ }^{3,4}$ )

Acknowledgement The author express his sincere thanks to Dr. S. Iwata of the Institute of Physical and Chemical Research for suppling the computer program. 